\title{
Educational infrastructure of Blagoevgrad District - A factor of labour demand and supply in the labour market (2001-2011)
}

\author{
Aleksandra Lyubenova Ravnachka \\ National Institute of Geophysics, Geodesy and Geography \\ Bulgarian Academy of Sciences \\ Akad. Georgi Bonchev 3, Sofia 1113, Bulgaria \\ ravnachka@abv.bg
}

\begin{abstract}
The paper analyses the educational infrastructure of Blagoevgrad district, the main characteristics and bureaus of vocational education, the type of training programs and their linkages with the specific expertise demand of the regional economy and the different communal services. Vocational education is crucial for the formation of knowledge and skills of the workforce and to overcome the gap between the qualitative characteristics of labour demand and jobs offered. The study covers the period 2001-2011 - the period when Bulgaria was preparing to join the European Union and when the country became a member of this organization. During that period, several changes in the educational system and the organization and functioning of the labour market occurred.
\end{abstract}

Keywords: Blagoevgrad district, Educational infrastructure, Vocational education, Labour demand and supply in the labour market.

\section{Introduction}

The aim of the current article is to reveal the specific features and the organization of the educational infrastructure in Blagoevgrad district (a NUTS 3 administrative-territorial unit). The emphasis is on the vocational education, the types of syllabus and their relation with the economic specialization of the district and its constituent municipalities. The vocational education is of key importance for the formation of knowledge and skills of the labour force and also for overcoming the mismatch between labour demand on the one hand and the jobs offered on the other.

The case study is based on Blagoevgrad district with a study period 2001-2011 and is a part of a doctoral thesis on "Spatial differentiations in the labour demand and job offers supply in Blagoevgrad district (2001-2011)”, which is to be completed by the end of 2014.

The development of education infrastructure and spatial distribution of its elements in Blagoevgrad district are important for the qualification and professional structure of the workforce and reduction of regional differences in the demand and supply. On the one hand this is imposed by the crossroad geographic location of the discussed district, its economic development, the ethno-confessional and 
the educational structure of the district population. The strategic geographic location, the proximity of FYROM (Macedonia) and Greece along with the existing 4 BCPs are all considered as favourable factors for attracting foreign investment for production development, trade and tourism development and also for the job-creation processes in the district (Fig. 1). This necessitates establishment of new courses in vocational and higher education, updating curricula and upgrading of the school buildings and infrastructure so that future workforce quickly adapt to the needs of the labour market and meets the business requirements by becoming a prepared staff with the necessary skills. On the other hand, the worsening demographic situation in the region, the reduction the number of school along with the increasing number of school dropouts requires timely changes in the structure and spatial organization of the education system in the district.

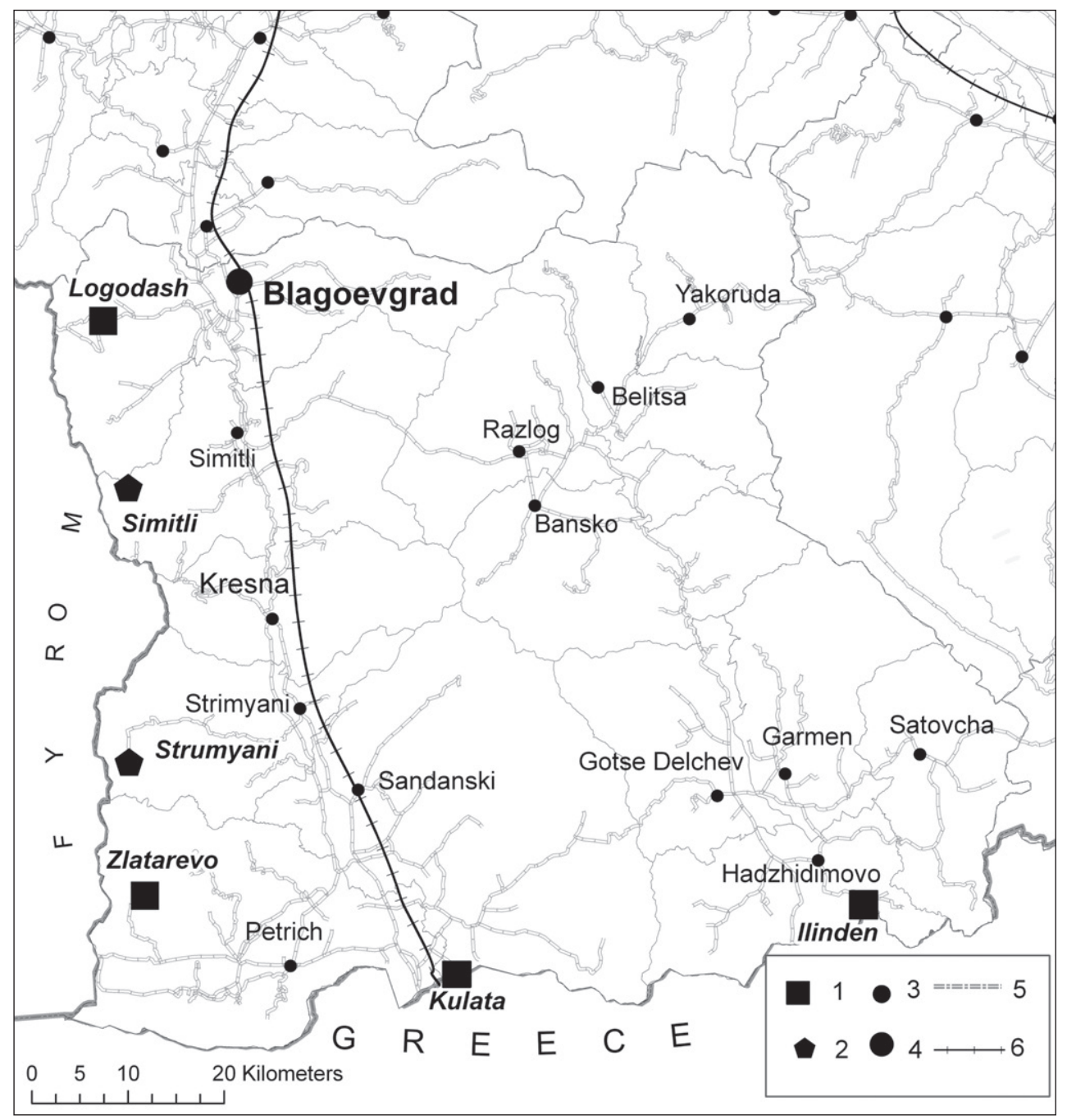

Figure 1. Border crossing points in Blagoevgrad district

1 - existing BCPs, 2 - planned BCPs, 3 - community centre, 4 - district centre, 5 - roads, 6 - railroads 


\section{Education infrastructure in Blagoevgrad District - nature and features}

According to the Education Act, the educational infrastructure includes:

- Pre-school education;

- General education;

- Vocational education;

- Higher education.

During the period 2001-2011 a lot of reforms took place in the educational infrastructure of Blagoevgrad district. This was the period when a great number of state and municipal schools were closed, private educational institutions were established, the profile and type of the subjects were changed, new curricula were introduced and the buildings were renovated.

In compliance with the state admission of students for the 2010/2011 academic year, there were 138 educational institutions in Blagoevgrad district, representing about $5 \%$ of the schools throughout the whole country and $21 \%$ of those in the South-western planning region of Bulgaria. Today Blagoevgrad district comes second after the capital city of Sofia in the South-western planning region in terms of the number of educational institutions. Around 50958 pupils and university students study in them. Taking into consideration the International Standard Classification of Education, these are the so-called general (comprehensive) schools that have a leading position in the district and the municipalities as a whole (Fig. 2.). They constitute $80.4 \%$ of the schools in the district ${ }^{1}$. Vocational education is offered in $13 \%$ of the educational institutions and the share of special schools is 3.6 $\%$. Blagoevgrad district has two universities (the South-western University "Neofit Rilski" and the American University-Bulgaria) as well as two colleges (the Vocational College of Economics and Management and the College of Tourism).
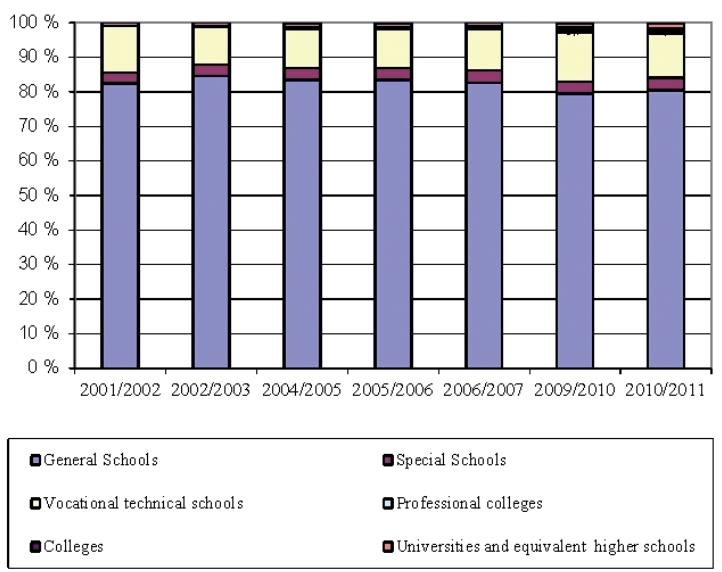

Figure 2. Structure of educational institutions in Blagoevgrad district

Source: Statistical Yearbook Blagoevgrad 2005, 2007, 2010; Areas, Districts and Municipalities

in the Republic of Bulgaria in 2010.

\footnotetext{
1 Excluding the kindergartens and the integrated children's establishments, consisting of crèches and kindergartens.
} 
During the period of investigation there was a tendency to reduce the number of educational institutions and students in Blagoevgrad. Reduction and aging of the population in the villages and small towns caused a decrease in the number of pupils and closure of some schools in them (Fig. 3). Central schools have been founded in the municipal centres, as well as several private comprehensive schools and a large number of training centres, located in the district centre and the municipal towns, where language and computer training and retraining of the workforce is performed.

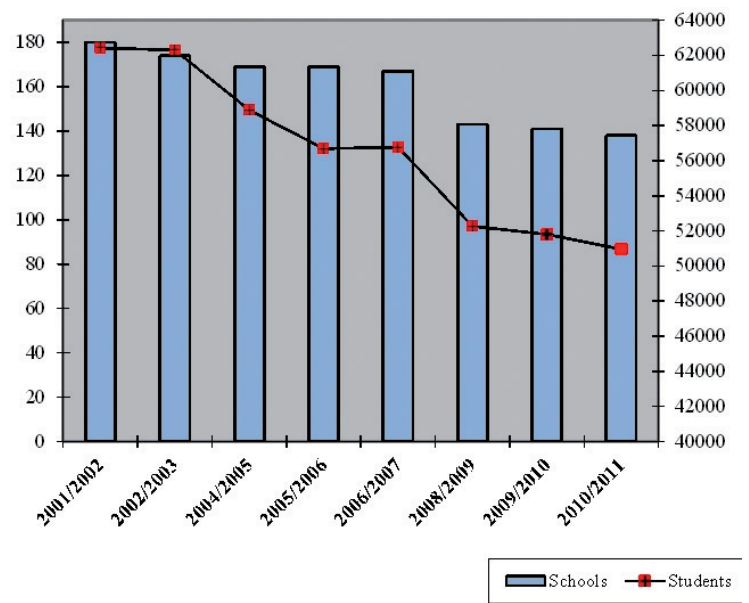

Figure 3. Dynamics of the number of schools and students in Blagoevgrad district Source: Statistical Yearbook 2001-2010, NSI.

In spite of the increasing birth rates since the beginning of the period of investigation the number of pupils subject to compulsory education was declining due to the out-migration flows. The number and share of pupils left the school, grew up. During the first term of the school year 2011-2012, 105 pupils left (of which 21 for unknown reasons, 30 because of poor performance and 54 for family reasons) compared to 85 during the same term of the school year 2004-2005. This was the effect of various factors: economic (low incomes or lack of such, worsening living standard), social, ethnical, etc. The children, who left for family reasons constituted the highest share (over $50 \%$ ) which can be explained with an increasing poverty, changes in the value system, etc. In consequence, the number of pupils, teachers and schools declined. In the near future the above mentioned negative tendencies will affect the number and quality of people entering the working age, and hence, the educational and professional structure of workforce in the district.

The structure of pupils throughout the period of investigation was dominated by the share of those who studied in general schools. Nevertheless, a downward trend in their number was observed. The situation in vocational secondary schools was similar. Only the number of university students in the district increased (Fig. 4). 


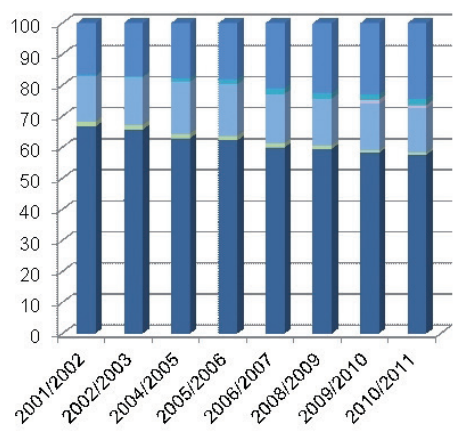

Universities and equivalent higher schools

m Colleges

Professional colleges

- Vocational technical schools

= Special Schools

- General Schools

Figure 4. Structure of students by types of schools in Blagoevgrad district

Source: Statistical Yearbook of Blagoevgrad - 2005, 2006 and 2007; National Statistical Yearbook 2010, NSI.

\section{Territorial organization of the educational infrastructure in Blagoevgrad District}

The current territorial organization of the educational infrastructure in Blagoevgrad district results both from the educational policy, implemented in the country before 1990, and from the policy consistent "with the present-day requirements and needs of society (in the economic, social, demographic and some other spheres)' (District Strategy for Regional Development..., p. 64). During the period of transition numerous transformations took place. On the one hand they were related to the change of status and closure of certain schools, and on the other - to the establishment of private educational institutions within the system of secondary and higher education.

There are considerable intraregional differences in the educational infrastructure of Blagoevgrad district between the municipalities as well as between the urban and rural settlements. The municipalities of Blagoevgrad, Petrich, Sandanski, Gotse Delchev and Razlog have the greatest number of schools (general and vocational) (Fig. 5). Those municipalities are most populated and economically developed, they are remarkable for the biggest share of people with secondary and higher education, and also for offering the largest number of jobs. 


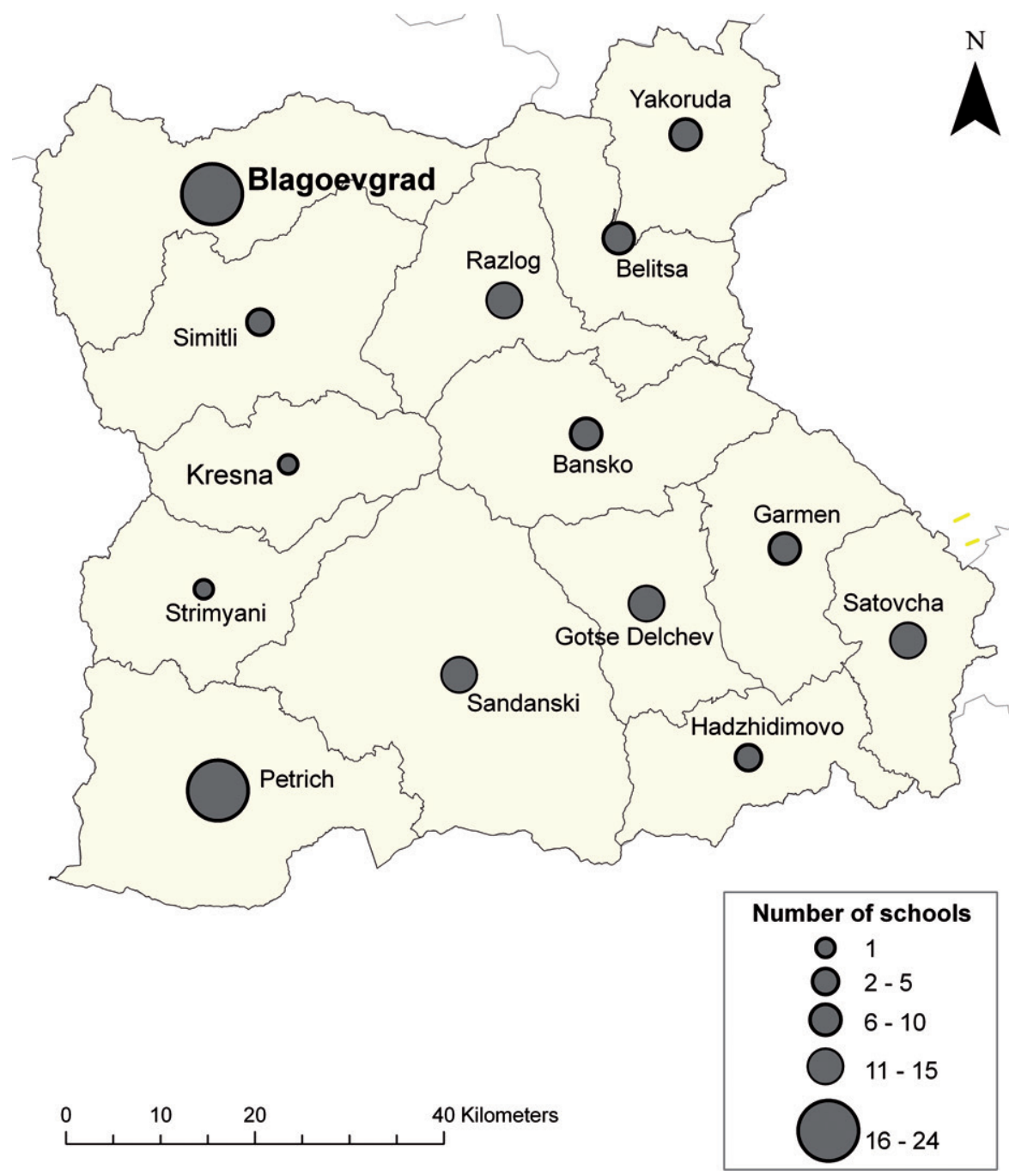

Figure 5. Territorial organization of the Educational infrastructure of Blagoevgrad district (2010/2011) Source: www.mon.bg.

Significant disproportions can also be observed between towns and villages with respect to the location of different types of schools. For example, $63 \%$ of the general schools are concentrated in the villages and $37 \%$ - in the towns. Among them the primary schools situated mainly in the rural settlements prevail. The prevalence of primary schools in villages is a result of an attempt to provide basic education to as many locations as possible. However, vocational training schools are distributed mostly in urban settlements because of the larger number of people and especially children and teenagers. Vocational schools are located in just 7 towns acting as municipal centres. There are special schools in 5 settlements (Blagoevgrad, Sandanski, Belitsa, Gotse Delchev and the village of Dolno Draglishte), which educate pupils from the whole country. Higher education institutions are to be found in the district centre - the town of Blagoevgrad. This is due to the mountainous 
landscape in some parts of the district, great distances of the settlements from the municipal centres and the out-migrations of young people, which results in a decrease in the number of children and in school closures. At the same time schools are shut down in the villages and small towns situated near the district centre and better developed community centres resulting in the improved facilities and equipment and a their more diversified profiles.

\section{Characteristic features and the territorial organization of vocational education and training in Blagoevgrad District}

This paper focuses particularly on the characteristic features and the territorial organization of vocational education and training in Blagoevgrad district.

Vocational education is essential for the formation of knowledge, skills and qualifications of workforce and for closure of the gap between the qualifications of the required workforce and the offered jobs. It is a key factor for the development of each country, each region or any other smaller territorial unit, 'for the development of high-tech economy as the knowledge economy is' (Todorova, S., p. 128). This result from the fact that the functioning of vocational schools and the training of students in different fields is largely depends on the economic conditions of the municipalities and the settlements, and on the demand for workforce with specific qualifications.

During the period 2005-2011 new educational standards were worked out providing for the acquisition of new knowledge and skills that the present-day and future workforce will need to find jobs in the labour market. The old tradition of having practical training in a number of businesses and manufacturing enterprises in the district was restored.

During the school year 2010-2011 the system of vocational education in Blagoevgrad district included 20 educational institutions, of which 18 were vocational secondary schools and 2 colleges with 8000 students approximately. The district incorporated about $18 \%^{2}$ of the vocational schools in the South-western planning region. Compared with the remaining districts in the region (excluding the capital city of Sofia), their share was big. Additionally, on the territory of Blagoevgrad district there were 19 centres for vocational training. The large number of professional schools, along with the influence of other factors led to an improvement of the educational structure of the population. During 2001-2011, the share of people with higher education increased by $4.1 \%$ points and those with secondary education by 7.5 percentage points. The share of persons with primary or lower education decreased by 11.3 percentage points. The increase in population with secondary education in municipalities Yakorouda (9.5\%) Hadzidimovo (9.5 \%) and Kresna (9\%) which also have the lowest educational level of the population area (Fig. 6) is meaningful. In those municipalities more than $50 \%$ of the population over 7 of age have primary or lower education.

2 Data for the academic years 2010/2011 


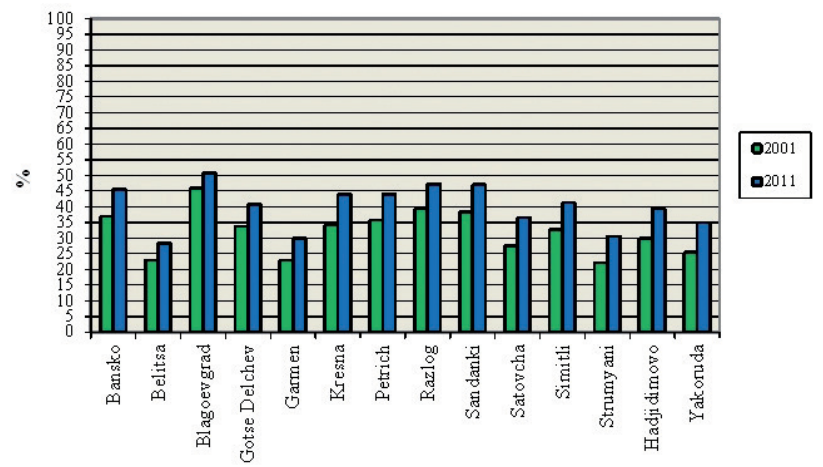

Figure 6. Change in the share of population with secondary education by municipalities in the Blagoevgrad district during the period $2001-2011$

Source: Statistical Yearbook of Blagoevgrad - 2002, National Statistical Institute, 2011.

The number of programs for permanent professional training of the employees has increased but the share of economically active population with higher and secondary education in the district (79.3\%) is still lower than that of the country as a whole (84.6\%) and its value in several other European countries.

\section{Presence or absence of correlation between vocational education of the population and the demand and supply of labour in the labour market in Blagoevgrad District?}

As already mentioned the vocational training is designed to prepare qualified personnel for the economic and social sphere - executive and management staff at low organizational and production level. The relationship between education and economic profile of an area and the municipality is twofold. On the one hand, the sector-specific industries of the district set the profiles and subjects to be taught in the vocational schools of the district on the basis of demand and supply of qualified workforce in the labour market. On the other hand, the professional education system forms the basic knowledge, skills and qualification of workforce. In this respect it should be noted that the specialization (profile) of the vocational schools has to be in line with the profile of the socio-economic complex in the individual municipality/region and to reflect the labour demand and supply. For example, the municipalities specializing in forestry and agriculture have vocational schools of forestry and agriculture. Such are the secondary schools in Razlog (Vocational School for Mechanization of Agriculture), in Bansko (Vocational Forestry School "N. Vaptsarov"), in Sandanski (Vocational School of Agriculture) and in Gotse Delchev (Vocational School for Mechanization of Agriculture "P. Yavorov"). They are of supra-municipal nature and teach students from the municipalities where there are no vocational schools. Some of them are of regional importance (e.g. the Vocational Forestry School “N. Vaptsarov”).

The vocational secondary schools in Blagoevgrad district educate future specialists in 50 subjects (Regional Inspectorate on Education, 2012); the highest share of pupils is recorded in the subjects "economic sciences and administration" and "electric engineering and electronics". The number of students in „Hotels and Restaurants” is increasing. But for economic development of the 
district also the manufacturing enterprises (textiles and clothing, food and drinks), tourism, building industry, trade, repair of cars and motorcycles are the most important. They have the greatest share of employed people in the district (Fig. 7). Also a mismatch between the profiles of vocational schools, preferences of students and the need of the labour market for workforce with the necessary education can be observed.
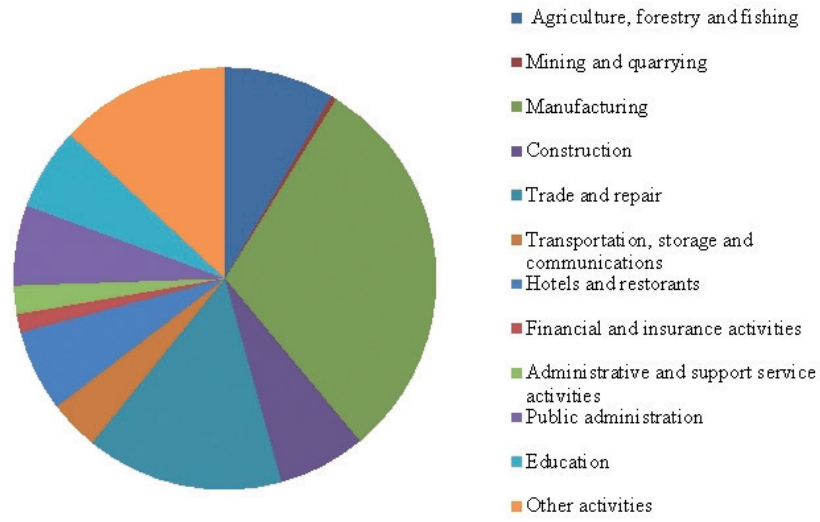

Figure 7. Structure of employed by economic sectors in Blagoevgrad district (2011) Source: Census of Population and Housing in 2011.

The analysis of the demand and supply in the labour market for the period 2001-2011 also showing some divergence between the needs of the labour market for specific professionals and profiles of vocational schools in the district. There is deficit of workforce in production activities with important implications for the regional economy - the apparel industry (seamstresses, ironers, machine operators), production of food and drinks, building industry (painters and masons), hotel and restaurant services (chefs, barmen, waiters, hotel receptionists, who speak foreign languages), as well as a shortage of sellers (Regional employment Service - Blagoevgrad).

The rapid development of tourism and the establishment of a number of localities as tourist centres required new courses related to hotel and restaurant management to be incorporated in the school curricula. These are, but not limited to: Hotel Management Organization (Bansko), Organization of Tourism and Leisure (Gotse Delchev), Catering Services, Restaurant Management (Razlog), etc. The elaboration of the curricula and teaching of these subjects offer good prospects in terms of the trends in the socio-economic development and employment level in the region, deindustrialization, promotion of small and medium family businesses (Mihailov, 2008 p.75). The expansion of financial services and the demand for specialists in the labour market during 2001-2005 encouraged additional grades to be taught in these fields.

Courses within the professional fields "restaurant and hotel management" are designed in most of the vocational secondary schools of the district. But teaching of the subjects such as "apparel industry, textiles and clothing" is not adequate. It is performed in two secondary schools only in two municipalities (Gotse Delchev and Blagoevgrad). The number of students and subjects in the sphere of food and drinks manufacture and building industry is insufficient. Besides, the number of those who wish to study forestry and agriculture is also decreasing. There is a discrepancy between the demand of businesses and the future specialists educated in the vocational schools. This is confirmed by the 
replies of two thirds of the interviewed managers in wearing apparel companies ${ }^{3}$ They answered to the question "Which are the strengths of your company in terms of human capital?" that people were their most important resource, but the majority of them didn't have the necessary skills and qualifications. For that purpose the production staff attends on-the-job training courses while the managerial staff addends special or standard training courses.

In Blagoevgrad district the system of professional education is notable for its territorial differentiation, conformable to the territorial distribution of population, to its educational structure and to the available workforce.

Vocational secondary schools are located in the most densely populated and the economically most advanced municipalities of the district (Fig. 8).

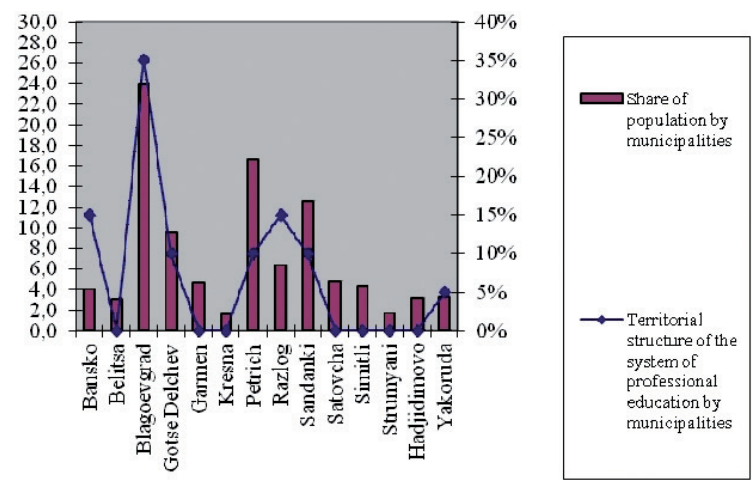

Figure 8. Territorial structure of the population and the system of professional education by municipalities in Blagoevgrad district (2011).

Source: National Statistical Institute.

In the Blagoevgrad district and particularly in the town of Blagoevgrad the share of vocational schools and students is the greatest. About $35 \%^{4}$ of the vocational schools concentrated in the district centre provide training to $33 \%$ of the students in the district. The municipality stands out for the greatest share of population with secondary education (50.7 \% in 2011).

The jobs and the corresponding occupations which the schools offer have been carefully selected from the "List of professions for vocational training" issued by the Ministry of Education and Science. To some extent they are consistent with the economic profile of the municipality and with the demand and supply of personnel in the labour market. A major disadvantage is considered to be the inadequate preparation of students for the manufacture of food stuffs, drinks and tobacco products. Some food and drinks manufacturing enterprises which operate in the municipality of Blagoevgrad (“Carlsberg Bulgaria”, “Carol Fernandez Meat” LTD, "Winery Upper Djumaya” Ltd. and etc.) need workforce with appropriate knowledge and skills. One of the biggest tobacco factories in the country - "Blagoevgrad-BT" which employs over 1000 people is also located in the district. In 5 of the vocational secondary schools throughout the district offer majors in the field of food technology, however, the level of training in those professions is deemed unsatisfactory and a decrease in number of students is observed.

\footnotetext{
3 The questionnaire was worked out for the MOVE Project in 2005

4 Data for the academic years 2010/2011
} 
In the municipalities of Bansko and Razlog there are vocational secondary schools (School of Agriculture and Tourism, School of Electronics and Energy, School of Tourism and Food Technology, Professional School of Agricultural Mechanization and the Professional School of Transportation) which offer a wide range of subjects in different spheres. The rapid growth of tourism, woodworking, agriculture and forestry in them as well as the demand for qualified workforce in these branches justifies the introduction of new subjects in the school curricula in the field of "organization of hotel management”, “tourism”, "restaurant management”, “farming”, “plant protection and agrochemistry", and "furniture production" (Vocational School of Agriculture and Tourism, Vocational School of Tourism and Food Technologies - Razlog, etc.). The development of electronics and electric engineering in the municipality of Razlog requires workforce with specific knowledge, skills and qualifications. This fact was pointed out by a respondent from the American plant "Magnetic Head Technologies" in 2005, who explained that the plant production needed qualified workers. The power of success lies in the staff, but in practice there is a shortage of workers with the necessary skills. The employees do on-the-job training courses. People are eager to work. Therefore, new subjects were proposed in the vocational schools for these fields.

In order to improve the economic conditions and to encourage the employment in Bansko municipalities, the system for training and requalification of the working age population in the municipality should be further developed. "A better coordination is to be achieved between the professional qualification of working age people in the municipality and the demand of the local labour market [...] and joint initiatives should be supported by municipalities, schools, businesses and non-governmental organizations for top-quality educational services and introduction of vocational training programs, consistent with the development priorities of the municipality and region” (Development Plan of the Municipality of Bansko ..., p. 41).

The vocational secondary schools in the municipalities of Gotse Delchev, Sandanski and Petrich provide training in "organization of tourism", "rural tourism”, "restaurant management”, "apparel industry”, "machines and equipment for food processing industry”, "electric engineering”, etc., which are in conformity with their economic profile. Children from the neighbouring municipalities, settlements and regions throughout the country come to study in these secondary schools. However, it is difficult to say whether these jobs are sought in the labour market because, on the one hand, there is no information, and on the other, the students out-migrate and continue their education in colleges and universities (Development Plan for the Municipality of Gotse Delchev during 20062013). In the period 2001-2011 a number of reforms took place in the system of vocational education of these municipalities to improve the quality and structure of school curricula, to introduce an obligatory foreign language training, to renovate the buildings and to raise the teachers' qualification. Alongside with these positive changes in municipalities Sandanski and Petrich the curricula must be up-dated in line with the new technologies, implemented in production, the cooperation between the educational institutions and the enterprises of the municipalities must be strengthened and the number of dropped-out students must be reduced (Municipal Plan for the Development of the Municipality of Petrich, 2007-2013). Should be ensured and more serious and quality training of the future workforce in the field of apparel industry and agriculture. These industries are the basis of their economic and social development.

In the municipality of Yakoruda there is a Vocational School of Engineering which trains students in the field of electric engineering and wearing apparel. No training is offered in subjects related to agriculture and forestry as well to tourism which results in discrepancy between the demand and supply of workforce in the labour market. The municipality is remarkable for the low education 
level of the population (34 \% of people have secondary education) and for a steady decrease in the number of children subject to compulsory education. In 2003 “...88.7 \% of the children, aged 7 to 18 , enrolled in schools. According to this indicator the municipality of Yakoruda ranks 123 among the total of 262 municipalities in Bulgaria. The main problems are the low incomes of the households, the occupation of children, aged 7 to 18, in the family business, and discouragement, caused by the lack of any prospects for future career" (Municipal Plan for the Development of the Municipality of Yakoruda,..., p.17).

In the remaining 7 municipalities of Blagoevgrad district there aren't vocational secondary schools. They are characterized with unsatisfactory economic and demographic conditions and with a low share of people with secondary education (about $35 \%$ ). This affects negatively the economic environment and the labour market.

In the municipalities of Hadjidimovo, Garmen, Satovcha and Belitsa there are favourable natural conditions for the development of tourism, agriculture, forestry and wood processing. But the lack of entrepreneurship, investments and educated and qualified workforce in them impede the use of natural resources. The share of people with primary or lower education is considerable as a result of the great number of old Bulgarian Mohammedans and Turks who are uneducated and are not involved in migration movements. Training and Retraining centres have to be established in these municipalities. The efforts of the Employment Agency must be directed towards closer cooperation with the workforce and students in order to help them in the choice of their future profession and to inform them better about the chances to find jobs in the labour market.

The municipalities of Simitli, Strumyani and Kresna have an extremely bad demographic situation, characterized by heavily aging population with a low educational structure. This necessitates a targeted policy aimed at increasing the birth rate, reducing the migration and improving the educational characteristics of the population in order to enhance its economic and social development.

\section{Conclusion}

On the basis of the investigations of the vocational education in Blagoevgrad district over the period 2001-2011, the following findings and recommendations are worth mentioning.

1. During the period 2001-2011, under the EU dynamic and rather complicated economic and social conditions, Bulgaria and the district of Blagoevgrad in particular, can boast about vocational education and training which considerably contribute to the formation of flexible and competitive workforce.

2. The permanent technological and information changes cause transformation in the branch structure of employment which requires strengthening of the relationship between vocational education (or any other type of education) and business sector, in order to prepare personnel with the necessary knowledge and skills.

3. The occupations and the related subjects, taught in schools, are carefully selected from the List of Professions for Vocational Education and Training, elaborated by the Ministry of Education and Science, and they are to a certain extent in conformity with the economic profile of the district and labour market.

4. A labour shortage has been established in the sphere of apparel industry, textiles and clothing and in the manufacture of food and drinks. Therefore, the number of subjects from the above mentioned spheres, and the number of students have to increase. 
5. The quality and attractiveness of vocational education have to improve and new and competitive professions have to develop, demanded by labour market, and guaranteeing its efficient functioning.

6. In order to improve the economic and social conditions in the poorest municipalities of the district, which incorporate the highest share of population with primary or lower education, it is necessary to take special measures and targeted actions, aiming to increase the number of people with secondary or higher education, to include a larger proportion of workforce in training courses and in the national and regional employment programs.

7. A better coordination should be promoted between the vocational schools and the enterprises which organize practical training for the students, thus helping them to adapt faster to reality.

8. Incentives are needed (both social and financial) to make more children from the poorest municipalities in the district (Satovcha, Garmen and Belitsa) enrol in schools. In addition, certain steps are to be taken to stop the tendency towards increasing the number and share of students, dropped out of the educational system.

9. Conclusion we can say, that the economy of Blagoevgrad district can be described as relatively well-developing. By GDP the district ranks 7th, while by GDP per capita - 14th (3rd in the Southwestern planning region of the country). The educational structure of the population is directly related to the economic orientation of the district. According the author's opinion, the economic branches that need to be developed should comply with the natural conditions and resources of the district (e.g. stimulation of spa tourism and agriculture).

\section{References}

Mihaylov, V., 2008, Development and management of human resources in north-western Bulgaria, Unpublished Ph.D. Thesis, Sofia, University St. Kliment Ohridski, 175.

Todorova, S., 2005. Education and access to educational institutions. Demographic development of the Republic Bulgaria, pp. 128 -136.

Areas Districts and Municipalities in the Republic of Bulgaria in 2010, NSI. http://www2.mon.bg.

Education Act, SG. 99 16.12.2011. http://www.erisee.org/downloads/2013/2/b/Education\%20Law \%202012\%20BL.pdf

Development Plan of the Municipality of Bansko 2007-2013, 2007, pp. 41. http://www.strategy. bg/StrategicDocuments/View.aspx?lang=bg-BG\&Id=24.

Development Plan for the Municipality of Gotse Delchev during 2006-2013, 2007. http://www. strategy.bg/StrategicDocuments/View.aspx?lang=bg-BG\&Id=28.

District Strategy for Regional Development of the administrative centre of Blagoevgrad for the period 2005 - 2015, 2005, pp. 64. http://www.strategy.bg. 
http://rcin.org.pl 